HU, Kaibao. Introducing Corpus-based Translation Studies. Heidelberg, New York, Dordrecht \& London: Springer-Verlag Berlin Heidelberg, 2016, 245 pp.

\title{
OS ESTUdOS DA TRADUÇÃO BASEADOS EM CORPUS GANHAM SEU PRÓPRIO "MAPA"
}

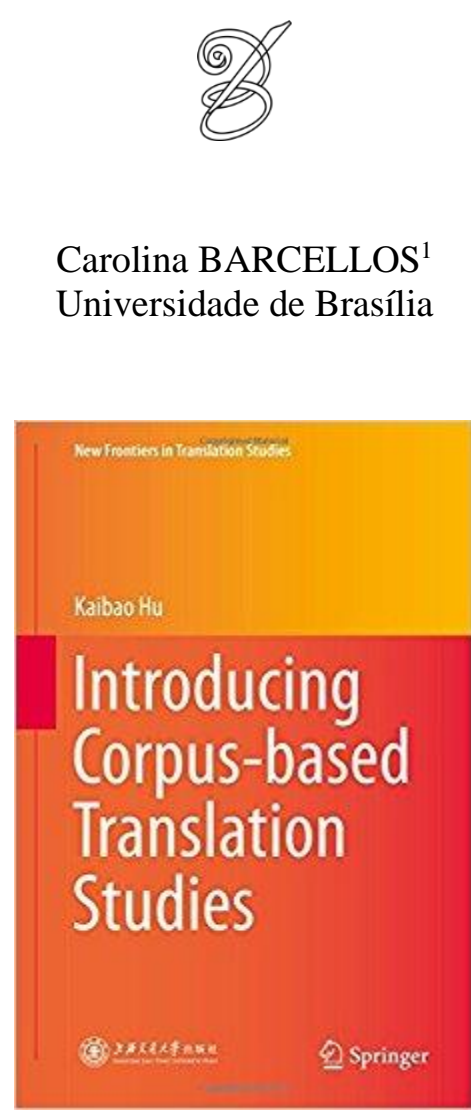

aibao Hu é um reconhecido pesquisador chinês que soma em seu currículo muitas
publicações sobre os Estudos da Tradução baseados em Corpus (ETBC). Durante
os últimos cinco anos, o pesquisador também passou a fazer parte do ambicioso projeto de montar um corpus paralelo, no par inglês-chinês, das obras de Shakespeare, na Universidade de Shanghai Jiao Tong. Sua experiência acadêmica produziu o livro Introducing Corpus-based Translation Studies. Logo no prefácio, Hu explica que escrever essa obra foi uma resposta a perguntas recebidas, com frequência ao longo dos anos, sobre a natureza dos ETBC, como funcionaria enquanto abordagem, possíveis metodologias de pesquisa e inúmeras discussões teóricas envolvendo seu escopo. A partir disso, o livro foi concebido para fornecer uma apresentação sistemática das áreas que compõem os ETBC, assim como 
reunir o arcabouço teórico que o qualificam como um novo paradigma dos Estudos da Tradução. É importante ressaltar que os ETBC nasceram nos anos 1990 e fazer pesquisa nessa área multidisciplinar por definição e dependente de softwares que, não raro, exigem uma série de adaptações para produzirem os resultados esperados ainda é um desafio.

O livro de Kaibao Hu contém nove capítulos e seu grau de especificidade é crescente, conforme convém a sua natureza de manual. A organização do livro de Hu lembra, inclusive, o conceito explorado em The map: A Beginner's Guide to Doing Research, de Andrew Chesterman e Jenny Williams, em que o objetivo era justamente fornecer um mapa aos estudantes dos Estudos da Tradução.

O primeiro capítulo foi apropriadamente chamado de introdução, mas se estende muito além do que se esperaria de uma seção com esse nome. Hu começa pela definição dos ETBC e acrescenta um panorama histórico de sua criação e desenvolvimento. Em seguida, são apresentadas publicações sobre os ETBC e conferências relevantes para a área como forma de situar pesquisadores interessados na associação entre tradução e corpora. Por fim, são apontadas as principais áreas dos ETBC e uma descrição geral do que o leitor pode esperar do 186 livro que tem em mãos. O trabalho se apresenta consistente e bem alinhavado. Já na introdução é possível perceber que o autor tem vasta experiência e fez sua lição de casa com diligência.

O segundo capítulo dá o passo mais lógico a partir de uma visão geral: conceitua corpus e apresenta seus diferentes tipos. O autor passa então a explicar os meandros do trabalho de compilação sem ser técnico demais. A obra em questão tem todas as características de um manual e isso fica cada vez mais claro à medida que se evolui na leitura. Percebe-se o esforço objetivo para mantê-la acessível e, ainda assim, bastante informativa. Esse segundo capítulo talvez seja o mais técnico do livro. Não surpreende, então, que o autor se concentre, logo em seguida, na apresentação dos diversos grandes corpora existentes no mundo.

O terceiro capítulo foca sua mira na influência dos Estudos Descritivos da Tradução no desenvolvimento dos ETBC. Nesse capítulo, é discutido principalmente o conceito de universais da tradução. Embora de forma simplificada, são trazidos à atenção do leitor vários desdobramentos dessa influência como, por exemplo, o estudo de colocações e da prosódia semântica.

O quarto capítulo se ocupa de um interesse crescente no escopo dos ETBC: a investigação do estilo do tradutor. É surpreendente a quantidade de trabalhos que Hu 
consegue concatenar aqui. O autor traz para a discussão o conceito de (in)visibilidade do tradutor e, logo, passa a uma análise das marcas deixadas pelo tradutor no texto traduzido apresentando nomenclatura técnica essencial aos estudos de estilo como o conceito de "voz do tradutor", cunhado por Theo Hermans em 1996, e o de "impressão digital”, cunhado por Mona Baker no ano 2000.

O quinto capítulo se concentra nas normas da tradução e na contribuição dos ETBC em relação a metodologias de pesquisa. Hu aponta, logo no começo do capítulo, que embora o estudo dessas normas seja muito antigo, metodologias efetivas de pesquisa só surgiram nos anos 1990, quando corpora passaram a ser usados para investigá-las. O capítulo inclui também um panorama sobre a natureza das normas da tradução e pesquisas a partir de perfis teóricos distintos. Nesse capítulo, há uma tabela que compara, de forma bastante didática, a categorização das normas da tradução segundo Toury, Chesterman, Nord e Hermans.

O sexto capítulo tem dois focos de concentração. Se, por um lado, começa abordando estudos de corpora sobre a prática tradutória, logo avança para discutir aplicações práticas do uso de corpora na prática tradutória. Nesse capítulo, surge a possibilidade de associar, perante o leitor, a pesquisa baseada em corpus com a prática do tradutor e os exemplos disso, talvez, sejam os mais claros para o pesquisador iniciante nos ETBC.

O sétimo capítulo se ocupa do uso de corpora no ensino da tradução. Para $\mathrm{Hu}$, as pesquisas sobre o ensino da tradução são muito menos numerosas que estudos sobre a prática tradutória. $\mathrm{O}$ autor defende que a formação de tradutores qualificados é bastante específica e demanda mais atenção da comunidade acadêmica. Além de um breve panorama sobre pesquisas dessa natureza, Hu aborda as especificidades do uso de corpus paralelo e de corpus comparável para o ensino da tradução. $\mathrm{O}$ autor também discute a aplicação de corpus para esse fim e como isso funcionaria, abordando desde a criação de currículos a metodologias de avaliação e exercícios. Por fim, Hu volta sua atenção aos livros didáticos e como o uso de corpora eletrônicos poderia ser útil para aprimorar recursos atualmente disponíveis. Para ele, a aplicação de corpora é capaz de tornar o ensino da tradução mais objetivo, visual, prático e autônomo.

O oitavo capítulo se dedica aos estudos de interpretação. Esse capítulo começa com um panorama sobre o desenvolvimento da interpretação, incluindo uma espécie de linha do tempo resumida de sua evolução desde os anos 1950. Em seguida, o autor passa a discutir a aplicação de corpora nos estudos da interpretação enfatizando, primeiro, as limitações práticas enfrentadas pelos pesquisadores para, logo depois, traçar um mapa do cenário 
científico atual. Hu aponta também como se daria a compilação de um corpus de transcrições da fala, oferecendo, inclusive, exemplos de convenções empregadas nessas transcrições, detalhes sobre a anotação dos textos e seu posterior alinhamento. $\mathrm{O}$ autor retoma noções já discutidas sobre normas e universais para apresentar pesquisas dos estudos de interpretação que se ocuparam em identificar elementos linguísticos específicos, dialogando com esses conceitos. Hu explica que o uso de corpora poderia ampliar ainda mais os horizontes dos estudos de interpretação, permitindo uma gama mais variada de interesses de pesquisa como, por exemplo, estilos de interpretação e métodos ou estratégias dos intérpretes.

O nono capítulo encerra o livro trazendo à tona uma discussão bastante necessária sobre as implicações e as limitações do uso de corpora, sobretudo em relação aos softwares disponíveis. Hu aponta como os ETBC permitiram a ampliação de horizontes de pesquisa e destaca uma série de obstáculos já enfrentados. O autor consegue, dessa forma, terminar seu livro como uma espécie de convite para possibilidades futuras na área, mesmo sem deixar de pontuar algumas das dificuldades que persistem na área.

Em geral, o livro apresenta-se de forma muito bem organizada e tem um texto de fácil

188 leitura. Há vários estudos de caso espalhados ao longo da obra. Cada capítulo começa com um resumo e termina com uma pequena conclusão, reunindo suas ideias principais, e com uma lista muito útil de referências bibliográficas. Deve-se ressaltar que a obra cumpre muito bem seu papel como um manual, embora não se destine apenas aos estudantes e pesquisadores iniciantes nos ETBC. Um dos pontos fortes do livro é seu caráter compreensivo, abrangendo vários aspectos do trabalho com corpora. $\mathrm{O}$ autor cita inúmeros trabalhos seminais da área e fornece um mapa bastante completo, capaz de orientar seu leitor em relação a próximas (e mais aprofundadas) leituras.

RECEBIDO EM: 31/10/2016

ACEITO EM: 05/03/2017

PUBLICADO EM: Junho de 2017

\footnotetext{
${ }^{1}$ Carolina Pereira BARCELLOS - Graduada em Letras Licenciatura Plena habilitação Português/Francês (2005) pela Universidade Federal de Pelotas (UFPel). Mestre (2010) e Doutora (2015) em Estudos Linguísticos pela Universidade Federal de Minas Gerais (UFMG). É professora adjunta no Bacharelado em Letras Tradução/Inglês na Universidade de Brasília (UnB). Brasília, Distrito Federal, Brasil.

Lattes: http://lattes.cnpq.br/0917397973726725 E-mail: cpbarcellos@gmail.com
} 